\title{
Occurrence, Levels and Spatial Distribution of Polybrominated Diphenyl Ethers: Case Study of Elemi River in Ado-Ekiti, Nigeria
}

\author{
Olayinka Abidemi Ibigbami* \\ *Department of Chemistry, Ekiti State University, P.M.B 5363, Ado- Ekiti, Nigeria. \\ *Corresponding Author Email: olayinkaibigbami@yahoo.co.uk \\ Received 11 November 2020, Revised 06 September 2021, Accepted 04 October 2021
}

\begin{abstract}
Polybrominated diphenyl ethers (PBDEs) were seasonally determined in water and sediments of the Elemi River, Nigeria using gas chromatography analysis. Samples were collected in two consecutive seasons for six months, monitoring the program every month. Three BDEs congeners $(28,47$ and 154$)$ were only detected with the mean concentration of ND $-0.001 \mu \mathrm{g} / \mathrm{L}$ and ND $0.143 \mu \mathrm{g} / \mathrm{kg}$ in water and sediments, respectively. BDEs $(99,100,153,183$ and 209) were consistently absent in both seasons. The distribution of BDEs showed that BDE 28 was consistently found in the water samples throughout the months of sampling, while the sediments sparingly contained BDE 28 and 47 . The study proposed the need for effective measures to reduce the deleterious contribution of these persistent compounds into the rivers.
\end{abstract}

Keywords: Polybrominated diphenyl ethers, Enrichment, Congeners, Gas chromatography

\section{Introduction}

Polybrominated diphenyl ethers (PBDEs) consist of 209 possible substances, called congeners. The available commercial PBDE products are mixtures of congeners. PBDEs are commonly used as flame retardants and are structurally similar to polychlorinated biphenyls (PCBs) [1, 2]. The environmental and health hazards of these chemicals have called for global concern. Due to their toxicity and persistence in the environment, the industrial production of some PBDEs has been restricted under the Stockholm Convention. PBDEs can be leached into the environment as a result of disposal when polymeric substances or products with sizeable quantities of PBDEs are exposed to the environmental conditions that support their leaching. Organohalogen compounds such as PCBs and PBDEs in water are of great concern for human health due to their persistent, toxic and bioaccumulative nature [3-6]. Research suggests that the penta-BDE formulation and its congeners tend to persist and bio-accumulate more readily in the environment, as compared to the other two formulations. As such, it is the most detected formula in wildlife and the environment, and one congener, in particular, BDE-47, is detected more often [7]. Various and significant levels of BDEs have been found in environmental matrices and biological samples such as blood, biota, breast milk, and adipose tissue. PBDEs have been reported in environmental matrices such as water $[4,8]$, sediment [9-11], and aquatic organisms [12]. In water, PBDEs are expected to adsorb strongly to suspended solids and sediments and bioconcentrate in aquatic organisms. The 
volatilization of PBDEs from water to air is expected to be attenuated by absorption in the water column. In soil, PBDEs are adsorbed strongly and will be immobile. Toxicological studies in animals have found nervous system damage, reproductive and developmental damage (e.g., reduced sperm production), endocrine disruption, and cancer following exposure to high doses of deca-BDE [13]. Endocrine disruption may result in developmental delays, decreased IQ, reproductive failure, and estrogen-related cancers.

Hence, the study assesses the occurrence, levels, and spatial distribution of PBDEs congeners in the Elemi River, Southwest Nigeria. The generated data of PBDEs in this study would not just complement the existing data, which is scanty in the Nigerian environment, but provide information to help in the scientific assessment of the impact of PBDEs on public health and aquatic environment in Nigeria.

\section{Materials and Methods Study Area}

Elemi river (Odo-ayo) in Ado-Ekiti is a tributary of the main river Elemi in IgedeEkiti. The river runs across the major road leading to Ado-Iworoko-Ekiti, where the samples were collected. Elemi is surrounded by a dense stretch of vegetation and an agricultural farm. The river serves as a good source of surface water that could be harvested to construct a water dam. Fig. 1 depicts the map of the study river and sampling locations.

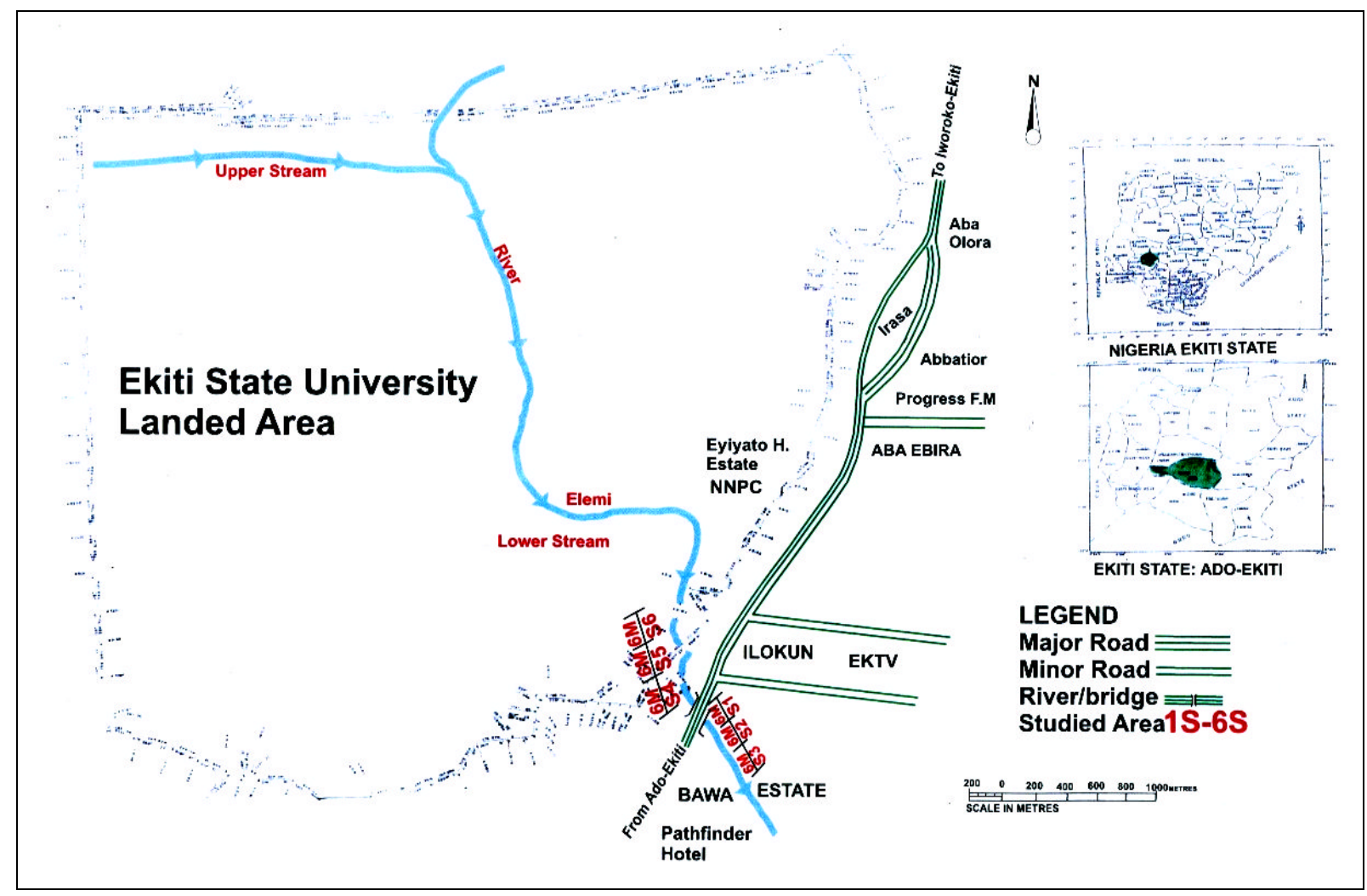

Figure 1. Map showing the study river and sampling locations Source: Department of Geography and Planning Science, Cartographic Unit, Ekiti State Uni versity, EKSU 


\section{Sample Collection and Preservation}

Sampling was conducted between the periods of 2017-2018, including the dry and wet seasons. Samples in the dry season were collected in December, January and February, while the wet season was done in May, June and July. The monitoring program was performed every month, where samples of water and sediments were collected from the studied river. Surface water samples $(10 \mathrm{~cm}$ below water level) were taken in glass sample bottles at six different spots (S1 to S6). Three samples (S1 - S3) and (S4 - S6) were poured together in glass bottles to obtain composite samples. The collected samples were kept in glass bottles, covered with screws and caps, and immediately transported to the laboratory for subsequent analysis. Sediment samples were taken as in the case of water samples. Sediments samples were taken from the same locations and time for water sampling at a depth of $5 \mathrm{~cm}$ using a pre-cleaned Ekman grab sampler. The sediment samples were air-dried for about two weeks in the laboratory, grind in an agate mortar, sieved through $2 \mathrm{~mm}$ mesh size and stored in glass sample bottles before analysis. Two composite samples of water and sediments were collected each month.

\section{Sample Extraction and Clean-up}

One hundred $(100 \mathrm{~mL})$ milliliters of the water sample was transferred into a clean $1 \mathrm{~L}$ separatory funnel where $40 \mathrm{~mL}$ dichloromethane (DCM) was added and shaken vigorously for about $20 \mathrm{~min}$. To ensure separation of the phases, the mixture was allowed for some time. The aqueous layer was removed after the separation of phases, while the organic layer was filtered into a $250 \mathrm{~cm}^{3}$ conical flask through anhydrous sodium sulphate $\left(\mathrm{Na}_{2} \mathrm{SO}_{4}\right)$ salt that has been prewashed with DCM. The extraction was repeated twice using a $40 \mathrm{~mL}$ portion of DCM and all the extracts were combined. The combined organic extracts were concentrated to $2 \mathrm{~mL}$ using a rotary evaporator at $40^{\circ} \mathrm{C}$.

For the sediments, samples extraction was carried out by EPA 3550C method as described by USEPA [14]. About $20 \mathrm{~g}$ of dried sample was mixed with anhydrous sodium sulfate $(1: 1, \mathrm{w} / \mathrm{w})$. The mixture was ultrasonically extracted with a $50 \mathrm{~mL}$ mixture of acetone and DCM $(1: 1, \mathrm{v} / \mathrm{v})$ for $45 \mathrm{~min}$ before being centrifuged for $10 \mathrm{~min}$. The supernatant was collected, and the extraction procedure was repeated thrice with a fresh 50 $\mathrm{mL}$ of acetone and DCM. The supernatants from the triplicate extraction were mixed. Through rotary evaporation, the mixture was concentrated to $\approx 2 \mathrm{~mL}$. The extract was redissolved in $5 \mathrm{~mL}$-hexane and later concentrated to $2 \mathrm{~mL}$ in a rotary evaporator at $40{ }^{\circ} \mathrm{C}$.

The column $15 \mathrm{~cm}$ (length) $\times 1 \mathrm{~cm}$ (internal diameter) for the extract clean-up was packed with different types of silica. The column packing involved using multilayer activated silica gel chromatography. Cotton wool was first clogged on top of the column. Sequential addition of $0.1 \mathrm{~g}$ activated silica, $0.2 \mathrm{~g}$ basic silica, $0.4 \mathrm{~g}$ acidic silica, $0.1 \mathrm{~g}$ activated silica, and $1.0 \mathrm{~g}$ of anhydrous $\mathrm{Na}_{2} \mathrm{SO}_{4}$ was done from the base. The packed column was first conditioned with $15 \mathrm{~mL}$ nhexane. The extract was introduced into the packed column and eluted with $100 \mathrm{~mL}$ hexane. The eluate was concentrated with a rotary evaporator under nitrogen flow for further chromatographic analysis.

\section{Gas Chromatographic Conditions}

For the gas chromatographic conditions of PBDEs: GC model: Agilent GC $7890 \mathrm{~A}$; the carrier gas flow rate was 2.0 $\mathrm{ml} / \mathrm{min}$; injector temperature: split injection: 20:1; carrier gas: helium; make-up gas: nitrogen; inlet temperature: $250{ }^{\circ} \mathrm{C}$; column type: HP 5MS; column dimension: $(30 \mathrm{~m} \mathrm{x}$ $0.25 \mathrm{~mm} \times 0.2 \mu \mathrm{m}$ ); oven programme: initial 
temperature at $100{ }^{\circ} \mathrm{C}$ and held for $1 \mathrm{~min}$, ramped at $30{ }^{\circ} \mathrm{C} / \mathrm{min}$ to $300{ }^{\circ} \mathrm{C}$, and held for 5 mins; detector: flame ionization detector (PFPD); detector temperature: $325{ }^{\circ} \mathrm{C}$; The total run time was 32 min.

\section{Quality Assurance Determination}

To determine any suspected possible traces of the studied PBDEs, solvents (similar volume) and anhydrous $\mathrm{Na}_{2} \mathrm{SO}_{4}$ used in the extractions were subjected to similar extraction and clean-up procedure as examined. Standard solutions of PBDEs were run in gas chromatography under set chromatographic conditions and mean peak areas were plotted against concentrations to obtain calibration curves of individual PBDEs. Retention windows were constant for the standard samples and were therefore relied on for component identification. The calibration was done by first analyzing/injecting mixture $(0.1,0.2,0.5$, and $1 \mathrm{mg} / \mathrm{L})$ of PBDEs standard into the Gas chromatography and plotting the calibration curves. The correlation coefficient was then calculated. The limits of detection (LOD) for the instrument were based on a signal to noise ratio of 3 and the limit of quantification (LOQ) was based on the signal to noise ratio of 10 . Overall, the extraction efficiency ranged between $92 \%$ and $97 \%$, while the samples' mean (standard deviation) percentage recovery was $93 \% \pm 4 \%$. Overall calibration graphs for individual PBDE congeners were linear with a correlation coefficients range of $0.9976-0.9999$. Hence, the results were acceptable, having met the quality assurance standard.

\section{Statistical Analysis}

The statistical analysis incorporated in work includes mean and corresponding standard deviation and coefficient of variation. Data obtained were also subjected to t-test, and Pearson correlation as applicable, using Statistical Software, SPSS Version 16.

\section{Results and Discussion}

Figure 2(a), 2(b-c), and 2(d) representative chromatograms of the PBDEs, sample, and blank, respectively. No interference peaks were obtained for the blank sample chromatogram at the same retention time as the target compounds. The summary of the PBDEs congeners measured in the water samples for both seasons is depicted in Table 1. Out of the eight BDEs congeners, only three (3), BDE-28, 47 and 154, were detected. The dry season samples only had BDE-28 with an average concentration range of $0.003-0.005 \mu \mathrm{g} / \mathrm{L}$, while the wet season contained BDE-28, 47 and 154 with a mean concentration of $0.0004-0.0023 \mu \mathrm{g} / \mathrm{L}$.

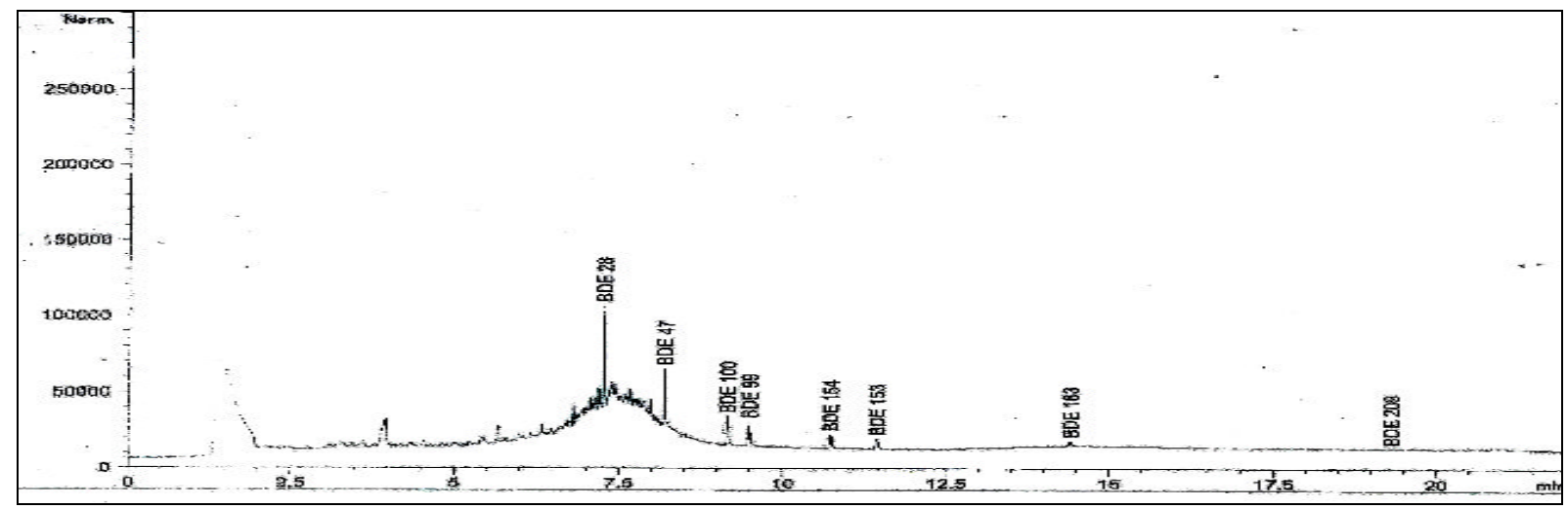

Figure 2(a). Representative chromatogram of a standard mixture of the target BDEs 


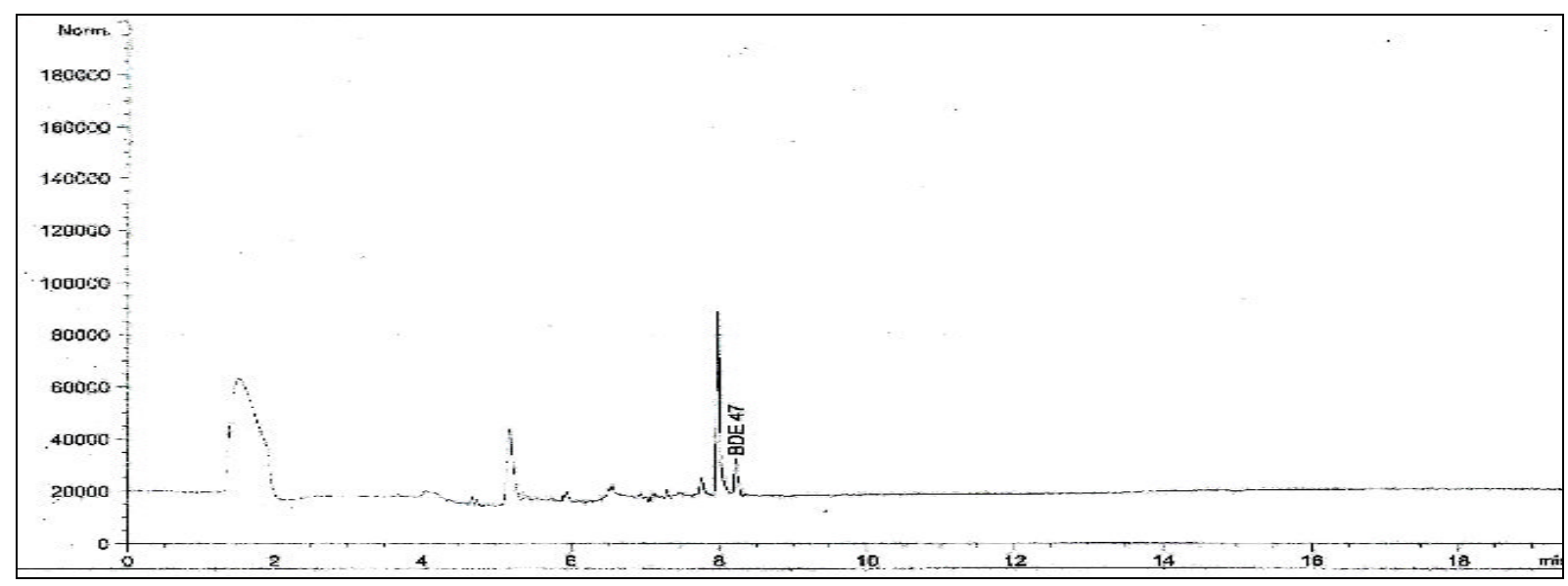

Figure 2(b). Representative chromatogram of the sample

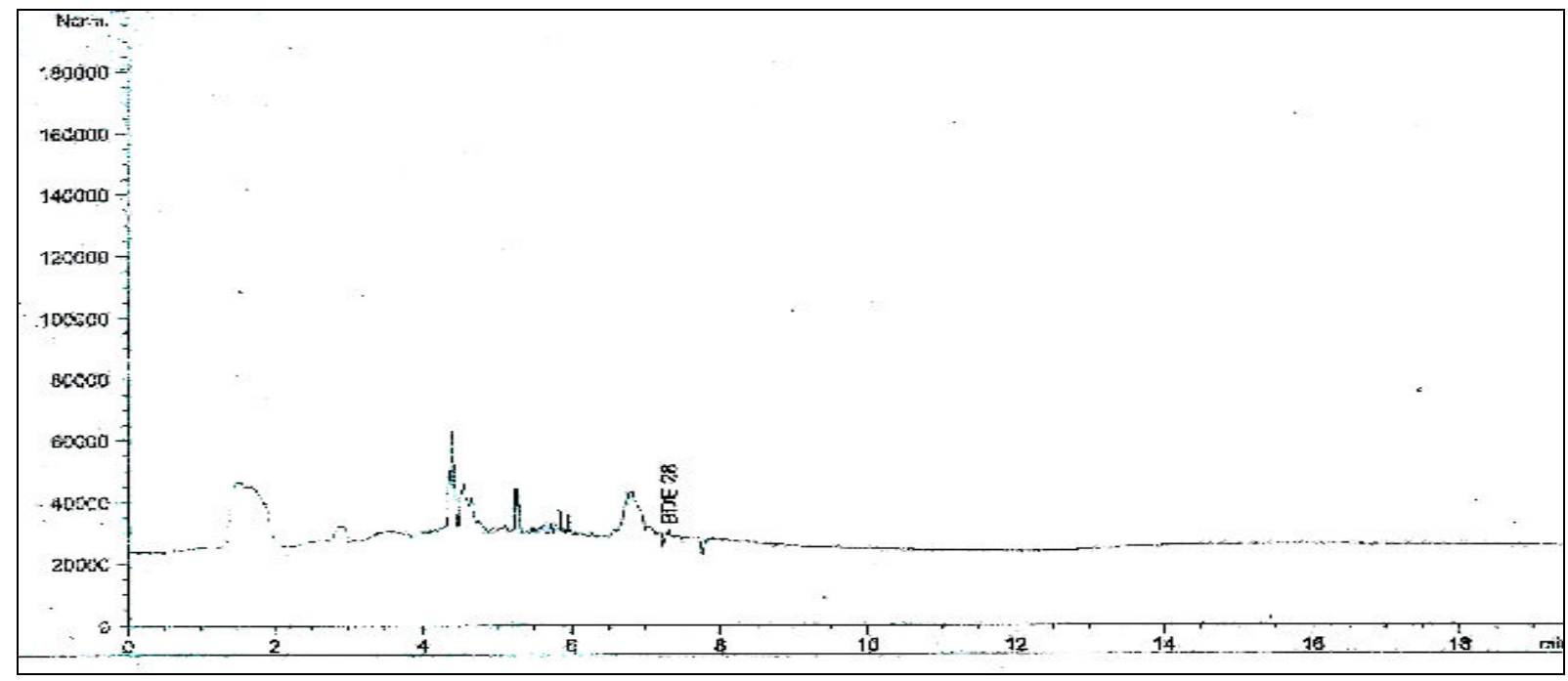

Figure 2(c): Representative chromatogram of the sample

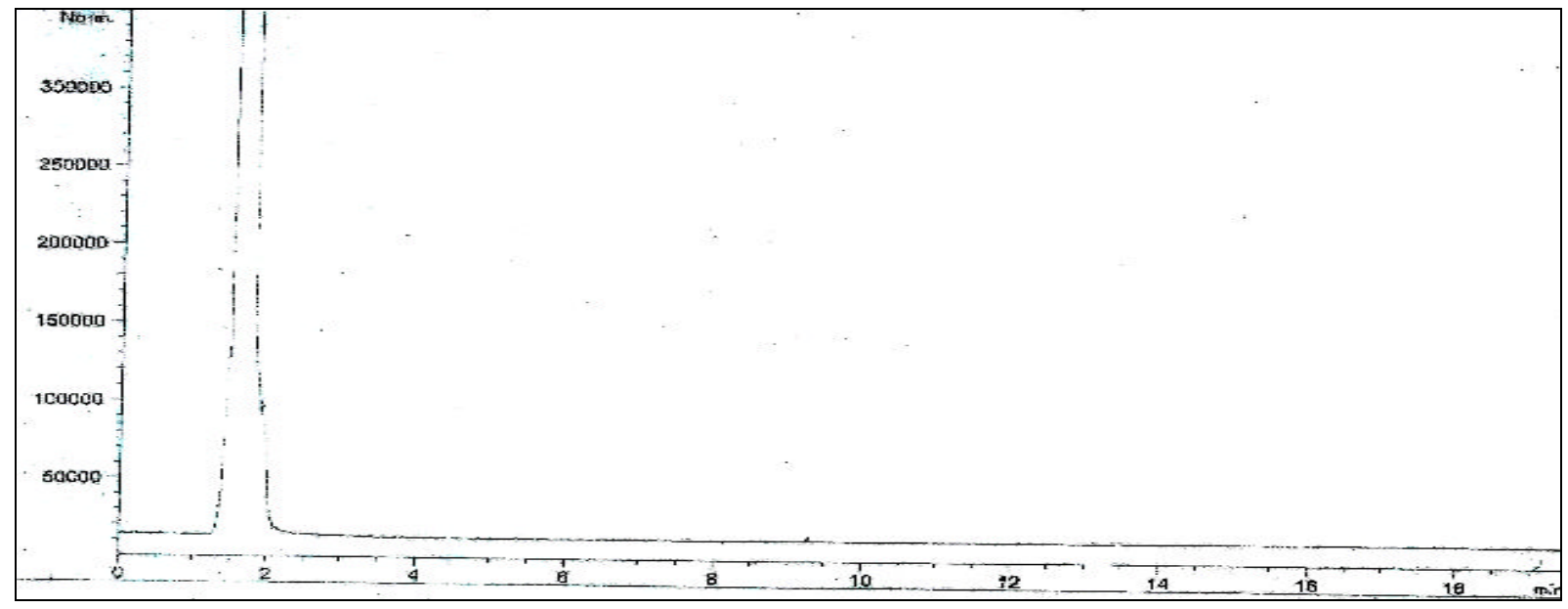

Figure 2(d). Representative chromatogram of the blank 
Table 1. Mean concentration ( $\mu \mathrm{g} / \mathrm{L})$ of PBDEs in the water samples of Elemi River during the wet and dry seasons.

\begin{tabular}{|c|c|c|c|c|c|c|c|c|c|c|c|c|}
\hline \multirow{2}{*}{ PBDEs } & \multicolumn{6}{|c|}{ Wet } & \multicolumn{6}{|c|}{ Dry } \\
\hline & May & Jun & July & Mean & $S D$ & $\mathrm{CV} \%$ & Nov & Dec & Jan & Mean & $S D$ & $C V \%$ \\
\hline BDE 28 & 0.0004 & 0.0008 & 0.0003 & 0.0012 & 0.001 & 85.9 & 0.003 & 0.0005 & 0.003 & 0.001 & 0.002 & 119 \\
\hline BDE 47 & - & - & 0.0006 & 0.0002 & 0.003 & 173 & - & - & - & - & - & - \\
\hline BDE 99 & - & - & - & - & - & - & - & - & - & - & - & - \\
\hline BDE 100 & - & - & - & - & - & - & - & - & - & - & - & - \\
\hline BDE 153 & - & - & - & - & - & - & - & - & - & - & - & - \\
\hline BDE 154 & - & 0.003 & - & 0.001 & 0.0017 & 173 & - & - & - & - & - & - \\
\hline BDE 183 & - & - & - & - & - & - & - & - & - & - & - & - \\
\hline BDE 209 & - & - & - & - & - & - & - & - & - & - & - & - \\
\hline$\sum$ PBDEs & 0.0008 & 0.0076 & 0.0058 & 0.0047 & 0.0035 & 74.4 & 0.006 & 0.001 & 0.006 & 0.002 & 0.003 & 119 \\
\hline
\end{tabular}

$\sum$ PBDE $=$ Sum of polybrominated diphenyl ethers

In general, BDE-99, 100, 153, 183 and 209 were not detected in both seasons. A high level of spatial variations exists in the concentrations of all the detectable BDEs, as shown in the calculated coefficient of variation $(85.9-173 \%)$.

The results indicated the predominant residues of BDE-28, as they were consistently found in all the samples every month. The $\sum$ PBDEs in the water samples ranged from $0.0008-0.0076$ and $0.001-0.006 \mu \mathrm{g} / \mathrm{L}$ in wet and dry seasons, respectively. The nondetectable or presence of BDE-99, 153 and 183 in the samples were comparably similar to Yang et al. [15] for nine water samples in China. The BDEs reported were comparably similar in most cases to Pei et al. [16] for Yellow river, China; while Diep river, South Africa [4], Asunle stream, Nigeria [17] were lower. The water from Jiaozhou Bay [18], Beijing River [19], Lake Michigan [20], San Francisco, USA [21] and Izmir Bay, Turkey [22] were higher than the present study. Higher levels of BDEs were reported in wet as compared to the dry season. A similar observation was reported in Asunle stream,
Nigeria, by Olutona et al. [17]. The level of PBDEs recorded in wet might be due to active mobilization of leached PBDEs congeners by erosion into water bodies during the rainy season.

The mean concentrations of BDEs in the sediment samples in both seasons are depicted in Table 2. The mean concentration in the sediments ranged from ND -0.090 $\mu \mathrm{g} / \mathrm{kg}$ in the dry season, while the wet reflected ND $-0.430 \mu \mathrm{g} / \mathrm{kg}$. Samples in dry only showed the presence of BDE 28 in January, while the wet season reflected BDE 28 and 47. In general, BDE 99, 100, 153, 154, 183 and 209 were not detected in both seasons. The BDE 28 and 47 level in the present study were comparably higher than what Pei et al. [16] (Yellow River, China), Mai et al. [23] (Shanghai River, China), Mariani et al. [24] (Maggiore Lake, Italy), Baron et al. [25] (Ebro River basin, Spain), Klosterhaus et al. [26] (Baikal Lake, Russia), Minh et al. [27] (Tokyo Bay, Japan) and Richman et al. [28] (Niagara, River, Canada) reported. 
Table 2. Mean concentration ( $\mu \mathrm{g} / \mathrm{kg})$ of PBDEs in the sediment samples of Elemi River during the wet and dry seasons.

\begin{tabular}{ccccccccccccc}
\hline \multirow{2}{*}{ PBDEs } & \multicolumn{1}{c}{ Wet } & \multicolumn{1}{c}{ Dry } \\
\cline { 2 - 12 } & May & Jun & July & Mean & SD & CV\% & Nov & Dec & Jan & Mean & SD & CV\% \\
\hline BDE 28 & 0.430 & - & - & 0.143 & 0.248 & 173 & - & - & 0.009 & 0.003 & 0.0052 & 173 \\
BDE 47 & - & 0.085 & 0.10 & 0.062 & 0.054 & 87.5 & - & - & - & - & - & - \\
BDE 99 & - & - & - & - & - & - & - & - & - & - & - & - \\
BDE 100 & - & - & - & - & - & - & - & - & - & - & - & - \\
BDE 153 & - & - & - & - & - & - & - & - & - & - & - & - \\
BDE 154 & - & - & - & - & - & - & - & - & - & - & - & - \\
BDE 183 & - & - & - & - & - & - & - & - & - & - & - & - \\
BDE 209 & - & - & - & - & - & - & - & - & - & - & - & - \\
IPBDEs & 0.860 & 0.170 & 0.200 & 0.410 & 0.390 & 95.1 & - & - & 0.018 & 0.006 & 0.010 & 173 \\
\hline
\end{tabular}

$\sum \mathrm{PBDE}=$ Sum of polybrominated diphenyl ethers

The study observed the predominant of BDEs in the rainy season. The predominance of BDEs (28, 47 and 154) could be due to the high technical formulation of the BDE introduction during this period. Congeners present in the waste, the discharge of PBDEs compounds into the river during the rainy seasons could also lead to greater contributions of BDEs in the river. PBDEs represent complex chemicals that consist of different members of bromine. The distribution pattern of the BDEs indicates congeners with three and four bromines majorly (BDE 28 and 47). The distribution of BDEs showed that BDE 28 was consistently found in the water samples throughout the months of sampling (Fig. 3), while the sediments sparingly contained BDE 28 and 47 (Fig. 4).

These showed that low halogenated PBDEs were the major constituent in the river and could have originated from the degradation of high PBDEs. Hua et al. [29] observed that deca-BDE and the commercial octa-BDE absorbed light up to $325 \mathrm{~nm}$, which indicates that these compounds may be susceptible to photodegradation at environmental wavelengths. Di- and tetra-
BDEs were reported to absorbed minimal light at wavelengths $>300 \mathrm{~nm}$. This trend suggests that the lower-brominated diphenyl ethers will be less susceptible to photolysis compared to octa-BDE and deca-BDE commercial mixtures. The commercial products of some PBDEs suggested historical use as the main source of PBDEs in the study area.

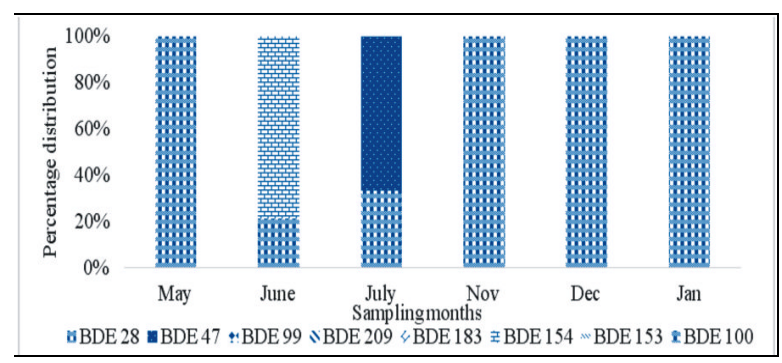

Figure 3. The distribution pattern of BDEs congeners in the water samples

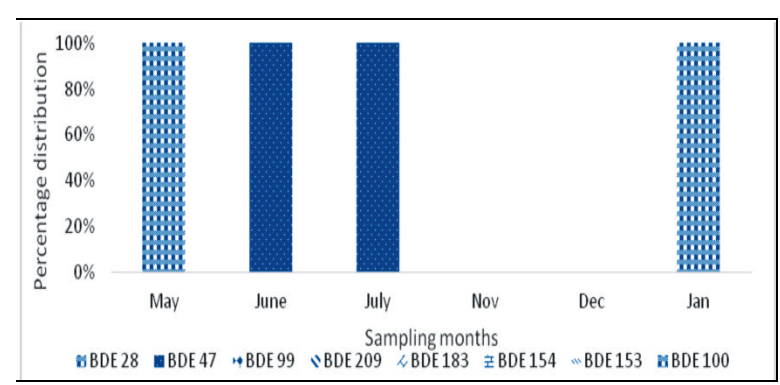

Figure. 4. The distribution pattern of BDEs congeners in the sediment samples 
From the statistical results, the correlation between the wet and dry seasons for water samples indicated a weak positive relationship, while sediments revealed a weak negative relationship at $p<0.05$. The $t$-test conducted on the results of water and sediments in both seasons revealed no significant difference $(p>0.05)$ between the dry and wet seasons. The positive correlation could be suggestive of similar sources, distribution patterns and the fate of these compounds in the aquatic environment. In contrast, the weak correlation observed in the sediments could suggest different accumulation and distribution patterns behavior. Comparing the levels of determined PBDEs in the water samples using analysis of variance (ANOVA), the results revealed a significant difference in the BDEs at $p<0.05$, while the sediment showed no significant difference in the data $(p>0.05)$. The study further revealed no significant difference in the determined levels of PBDEs in water and sediment $(p>0.05)$.

\section{Conclusion}

The study revealed the presence and trace levels of three BDEs (28, 47 and 154) congeners in the sampled river. The results showed that low halogenated PBDEs were the major constituent in the river and could have originated from the degradation of high PBDEs. A high level of spatial variations exists in the concentrations of all the detectable BDEs. Thus, accumulation and biomagnification of PBDEs residues in aquatic ecosystems are expected. Based on the above findings, the study recommends the possible evaluation programs for PBDEs in water bodies (rivers and oceans) within the State and environs.

\section{Acknowledgment}

The author acknowledges the technical assistance rendered by the Chemical
Laboratory of Nigerian Institute of Oceanography and Marine Research, Victoria Island, Lagos, Nigeria.

\section{Conflict of interest}

The author declare that there is no conflict of interest.

\section{References}

1. F. Rahman, K.H. Langford, M.D. Scrimshaw and J.N. Lester, Sci. Total Environ., 275 (2001) 1. http://doi:10.1016/s00489697(01)00852-x

2. M. Alaee, P. Aris, A. Sjodin and A. Bergman, Environ. Int., 29 (2003) 683. http://doi:10.1016/S01604120(03)00121-1

3. H. B. Moon, M. Choi, J. Yu, J., R. H. Jung and H. G. Choi, Chemosphere, 88 (2012) 837.

http://doi:doi10.1016/j.chemosphere.201 2.03.091

4. A, P Daso, O. S. Fatoki and J.P. Odendaal, Environ. Sci. Pollut. Res., 20 (2013) 5168.

http://doi:10.1007/s11356-013-1503-6

5. H. Hellar-Kihampa, K. De wael, E. ELugwisha, G. Malarvannan, A. Covaci and R. van Grieken. Sci. Total Environ., 447 (2013) 186.

http://doi:10.1016/j.scitotenv.2012.12.083

6. Y. Yang, X. Yun, M. Liu, Y. Jiang, Q. Li and I. Wang, Environ. Sci. Pollut. Res., 21 (2013) 1. http://doi:10.1007/s11356-013-2269-6

7. K. S. Betts, Environ. Sci. Technol., 36 (2002) 50.

http://doi.org/10.1021/es022197w

8. M. Gonzalez, K. S. B. Miglioranza, S. I. Grondona, M. F. S. Barni, D. E. Martinez and A. Pena, Environ. Sci. Process. Impacts, 15 (2013) 739. http://doi.org/10.1039/C3EM30882K

9. N., Bodin, R. N' Gom Ka, F. Le Loc'h, J. Raffray, H. Budzinski, L. Peluhet and 
M. Tito de, Chemosphere, 84 (2011) 318.

http://doi:10.1016/j.chemosphere.2011.04.012

10. O. Olukunle, J. Okonkwo and O. Odusanya, Accelerated solvent extraction of common polybrominated diphenylethers from river sediments, Tshwane University of Technology and Department of Water Affairs: Tshwane, South Africa, (2011) 1.

https://wisa.org.za/wp-

content/uploads/2018/12/WISA2012P085.pdf

11. G.O. Adewuyi and A.O. Adeleye, Afr. Environ. Sci. Technol., 7 (2013) 686. http://doi.org/10.5897/AJEST2013.1488

12. V. Wepener, N. Smith and A. Covaci, Bull. Environ. Contam. Toxicol., 88 (2012) 277. http://doi:10.1007/s00128-011-0439-0

13. P. O. Darnerud, Environ. Inter. 29 (2003) 841.

http://doi.org./10.1046/j.1365.3040.2003.00878.x

14. US Environmental Protection Agency. SW-846, test methods for evaluating solid waste, $3^{\text {rd }}$ edn. Update IVB. Chapter 4, organic analytes. US EPA, Washington, DC (2000). www. wbdg. org $>$ FFC $>$ EPA $>$ EPACRIT $>$ epa_sw_846

15. Y. Yang, Q. Xie, X. Liu and J. Wang, Ecotoxicol. Environ. Safety, 115 (2015) 55.

http://dx.doi.org/10.1016/j.ecoenv.2015.02.006

16. J. Pei, H. Yao, H. Wang, H. Li, S. Lu, X. Zhang and X. Xiang, Marine Pollut. Bull., 129 (2018) 106. http://doi.org/10.1016/j.marpolbul.2018.02.017

17. G. O. Olutona, J. A. O. Oyekunle, A. O. Ogunfowokan and O. S. Fatoki, Toxics, 5 (2017) 1.

http://doi:10.3390/toxics 5020013

18. T. Ju, W. Ge, T. Jiang and C. Chai, Sci. Total Environ., 557 (2016) 571. http://doi.org/10.1016/j.scitotenv.2016.03.013

19. J. Xiong, G. Li, T. An, C. Zhang and C. Wei, Environ. Pollut., 219 (2016) 596. http://doi.org/10.1016/j.envpol.2016.06.021

20. S.S. Streets, S.A. Henderson, A.D. Stoner, D.L. Carlson, M.F. Simcik and D.L. Swackhamer, Environ. Sci. Technol. 40 (2006) 7263. http://doi.org/10.1021/es061337p

21. D. R. Oros, D. Hoover, F. Rodigari, D. Crane and J. Sericano, Environ. Sci. Technol., 39 (2005) 33. http://doi:10.1021/es048905q

22. B. Cetin and M. Odabasi, Environ. Sci. Technol., 41 (2007) 785. http://doi.org/10.1021/es061368k

23. B. X. Mai, S. J. Chen, X. J. Luo, L. G. Chen, O. S. Yang, G. Y. Sheng, P. G. Peng, J. M. Fu and E. Y. Zeng, Environ. Sci. Technol., 39 (2005) 3521. http://doi.org/10.1021/es048083x

24. G. Mariani, E. Canuti, J. CastroJimenez, E.H. Christoph, S.J. Eisenreich, G. Hanke, H. Skejo and G. Umlauf, Chemosphere, $73 \quad$ (2008) 114. http://doi.org/10.1016/j.chemosphere.20 07.02.071

25. E. Baron, G. Santin, E. Eljarrat and D. Barcelo, J. Hazard. Mater., 265 (2014) 288.

http://doi.org/10/1016/j.jhazmat.2013.10.069

26. S. L. Klosterhaus, H. M. Stapleton, M. J. La Guardia and D. J. Greig, Environ. Int., 47 (2012) 56.

http://doi:10.1016/j.envint.2012.06.005

27. N. H. Minh, T. Isobe, D. Ueno, K. Matsumoto, M. Mine, N. Kajiwara, S. Takahashi and S. Tanabe, Environ. Pollut., 148 (2007) 409. http://doi:10.1016/j.envpol.2006.12.011

28. L. A. Richman, T. Kolic, K. Mac Pherson, L. Fayez and E. Reiner, Chemosphere, 92 (2013) 778. http://doi.org/10.1016/j.chemosphere.20 13.04 .011

29. I. Hua, N.G. Kang, C.T. Jafvert, and H.R. Fabregas-Duque, Environ. Toxicol. Chem., 22 (2003) 798. http://doi.org/10.1002/etc.5620220418 